\title{
Modified technique for transscleral fixation of posterior chamber intraocular lenses
}

\author{
Chongde Long ${ }^{\dagger}$, Yantao Wei $^{\dagger}$, Zhaohui Yuan, Zhiqing Zhang, Xiaofeng Lin and Bingqian Liu
}

\begin{abstract}
Background: Suture exposure remains to be a potential problem of transscleral fixated posterior chamber intraocular lens (PCIOL). We report a modified technique to minimize the risk of suture exposure for the transscleral fixation of PCIOL.

Methods: The modified surgical technique is as following: at first, two $3 \mathrm{~mm} \times 4 \mathrm{~mm}$ square scleral pockets were created from groove incisions at opposite positions. A straight needle attached to a 10-0 polypropylene suture was passed through one incision groove. Then, a 27-Gauge hollow needle passed through the opposite sclera incision bed was used to retrieve the straight fine needle via its barrel. The sutures were tied to themselves after one more bite on the scleral bed. At last, the suture ends were left long (about $4 \mathrm{~mm}$ ) and laid flat into corresponding laminar scleral pockets. This modified technique of PCIOL was performed in 48 post-traumatic aphakic vitrectomized eyes from 48 patients (47 male, one female) with mean age of $34.8 \pm 14.8$ years. Main outcome measures included best corrective visual acuity (BCVA), IOL decentration, IOL tilt, and postoperative complications.
\end{abstract}

Results: The mean follow-up was $32.3 \pm 10.8$ months (3-67 months). The LogMAR BCVA remained stable, from a preoperative value of $0.46 \pm 0.34$ to postoperative $0.44 \pm 0.34(p=0.69)$. Mild IOL tilt $\left(5-10^{\circ}\right)$ was observed in five eyes, and slight IOL decentration $(0.5-1.0 \mathrm{~mm})$ was seen in three cases. No case of suture exposure, suture breakage, IOL dislocation, or endophthalmitis was observed during the follow up period.

Conclusion: The modified technique allowed stable placement of PCIOLs in post-traumatic aphakic eyes with a wide range of follow-up. Our procedure might have the potential benefit to avoid suture exposure in scleral-fixated IOL implantation.

Keywords: Aphakic eye, Posterior chamber intraocular lens, Transsclera suture fixation, Suture exposure

\section{Background}

There are several surgical techniques for intraocular lens (IOL) implantation in the absence of capsular support [1]. Transsclerally fixated posterior chamber intraocular lens (PCIOL) is an effective way to correct aphakia [2-11], especially for those patients with corneal disease, iris tissue damage, angle abnormalities, or glaucoma. Being located in a position closest to the original lens, PCIOL possesses several inherent advantages: it does not contact with corneal endothelium or trabecular meshwork; acts as a mechanical barrier between vitreous cavity and anterior chamber.

\footnotetext{
* Correspondence: bingqianliu@gmail.com

${ }^{\dagger}$ Equal contributors

From the State Key Laboratory of Ophthalmology, Zhongshan Ophthalmic

Center, Sun Yat-sen University, 54 South Xianlie Road, Guangzhou 510060, Guangdong, China
}

However, tie erosion and suture exposure remains to be a potential problem in transsclerally sutured PCIOL $[12,13]$. The reported incidence rate of suture exposure was from 6.7 to $73.0 \%$ [12-18].

Several techniques have been described to avoid suture erosion as there is a potential risk to develop endophthalmitis and IOL dislocation, including rotation the suture knots into the eye $[8,19]$, suturing within a scleral groove [20], burying the suture ends into scleral tunnel [21], covering the suture ends with fascia lata [6], tenon's capsule [22], scleral flap [10, 23-27] or scleral pocket [28]. The aim of this study was to assess the long-term safety and efficacy of a variation of the scleracovering technique for suture fixation of PCIOLs in a series of post-traumatic aphakic eyes, in which the 
suture ends were left long and laid flat in laminar scleral pockets, minimizing the risk for suture exposure.

\section{Methods}

This study was conducted in compliance with the principles of the Declaration of Helsinki and was approved by the Ethics Committee of Zhongshan Ophthalmic Center, Sun Yat-sen University. Informed written consent was obtained from all the patients or guardians prior to surgery.

The inclusion criteria: total lens capsule absence in post-traumatic eyes; the minimal time between the primary surgery (pars plana vitrectomy or wound closure) and the PCIOL implantation was 3 months; the retina of the aphakic eye remained attached; no active inflammation was found in the aphakic eyes. A retrospective chart review was conducted of transscleral sutured PCIOL implantation in post-traumatic aphakic eyes performed by single surgeon (C.L.) from May 2007 to December 2013 using the new technique, which was designed to minimize the risk of suture exposure. The capsule, including the posterior and the anterior capsule, was totally compromised in all of the cases. Data collected included, ocular trauma history, preoperative and final BCVA, preoperative and postoperative intraocular pressure (IOP), and postoperative complications.

\section{Surgical technique}

All the surgeries were performed by the same surgeon (C.L.). The surgical technique was individualized because of the trauma history and the complicated nature of the eyes resulted from previous surgery. For eyes with a history of pars plana vitrectomy $42 / 48$ (87.5\%), a 23 - or 20-Gaugue infusion cannula was inserted to maintain the intraocular pressure at $3.5 \mathrm{~mm}$ posterior to the limbus into the eye to prevent intraoperative globe collapse. The surgical steps (Additional file 1) are shown below:

Two $3 \mathrm{~mm}$ limbus-parallel half-thickness scleral incisions (1.5 mm behind the posterior surgical limbus) were made directly opposite each other (Fig. 1a). Then, two $3 \mathrm{~mm} \times 4 \mathrm{~mm}$ scleral pockets were created with a blade to extend the incision bed posteriorly (Figs. $1 \mathrm{~b}$ and $2 \mathrm{a}$ ).

A straight needle attached to a $10-0$ polypropylene suture was passed through the bed of one laminar scleral incision (1 o'clock). The needle was placed perpendicular to the sclera wall and then parallel to the iris until its tip appeared in the center of the pupil. A 27-Gauge hollow needle passed through the opposite sclera incision bed $(1.5 \mathrm{~mm}$ behind the posterior surgical limbus at 7 o'clock) was used to retrieve the straight fine needle via its barrel (Figs. 1c and 2b). The straight fine needle was withdrawn from the eye guided by the hollow needle, leaving the $10-0$ suture traversing the eye from one scleral bed to the other.

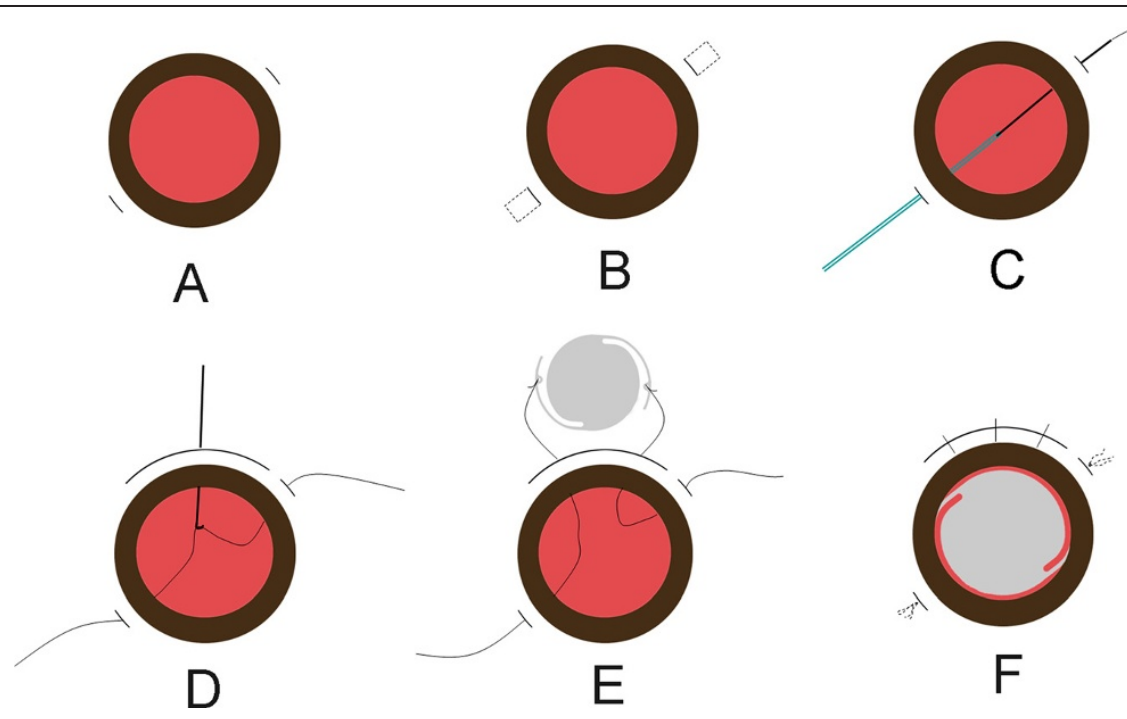

Fig. 1 Schematic procedures of modified technique for PCIOL fixation. a Two $3 \mathrm{~mm}$ limbus-parallel half-thickness scleral incisions were made directly opposite each other, at 2 o'clock and 8 o'clock, $1.5 \mathrm{~mm}$ behind the limbus. b Two $3 \mathrm{~mm} \times 4 \mathrm{~mm}$ scleral pockets were created with a blade to extend the incision bed posteriorly. $\mathbf{c}$ A straight needle attached to a 10-0 polypropylene suture was passed through the bed of laminar scleral incision at 2 o'clock. A 27-Gauge hollow needle passed through the opposite sclera incision bed at 8 o'clock was used to retrieve the straight fine needle via its barrel. $\mathbf{d}$ A superior corneoscleral incision was made. The suture loop was retrieved through the superior limbal wound. e The loop was cut and the ends were tied to the haptics of the IOL respectively. $\mathrm{f} \mathrm{A} \mathrm{PCIOL} \mathrm{was} \mathrm{inserted} \mathrm{into} \mathrm{posterior} \mathrm{chamber} \mathrm{through} \mathrm{the} \mathrm{superior} \mathrm{incision,}$ and placed in the ciliary sulcus followed by pulling the sutures to center the optics. The superior corneoscleral wound was closed. The sutures were tied to themselves after one more bite on the scleral bed. The suture ends were left long $(4 \mathrm{~mm})$ and laid flat into the scleral pockets 


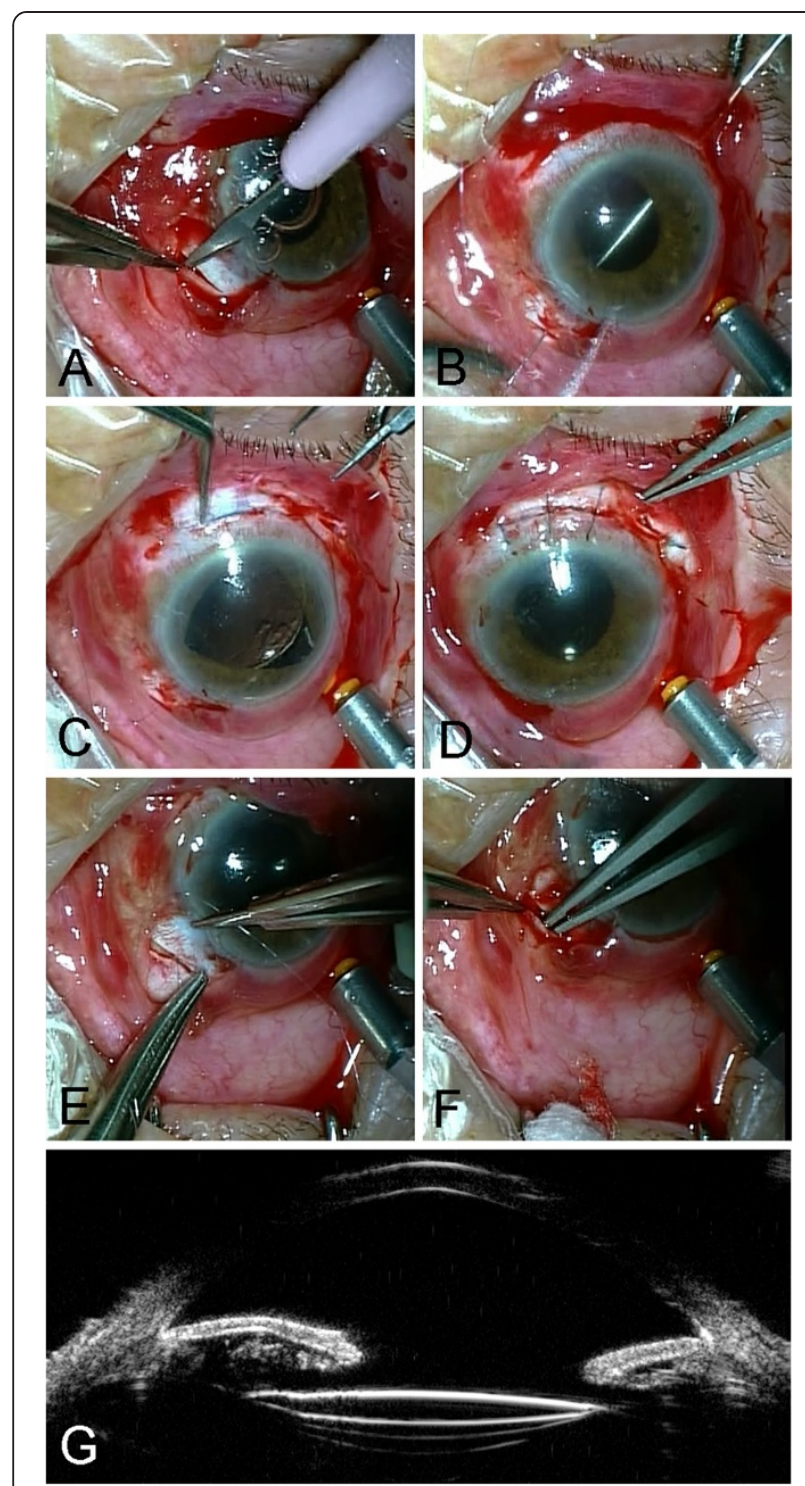

Fig. 2 Modified technique for $P C I O L$ fixation. a A scleral pocket was created with a blade. $\mathbf{b}$ A hollow needle passed through the opposite sclera incision bed to retrieve the straight fine needle via its barrel. c A PCIOL was inserted into posterior chamber through the superior incision. $\mathbf{d}$ The superior corneoscleral wound was closed. e One tick bite on the scleral bed was done with the short needle connected to the suture. $\mathbf{f}$ The suture ends were laid flat into the scleral pocket. g A typical UBM imaging with a PCIOL implanted

A superior corneoscleral incision was fashioned for implantation of the IOL. The suture loop was retrieved through the superior limbal wound (Fig. 1d). The loop was cut and the ends were tied to the haptics of the IOL respectively (Fig. 1e). The IOL was inserted into posterior chamber through the superior incision (Fig. 2c), and placed in the ciliary sulcus followed by pulling the sutures to center the optics. Severe iris and pupil damage was repaired. The superior corneoscleral wound was closed (Fig. 2d). The sutures were pulled gently and tied to themselves after one more bite on the scleral bed (Fig. 2e). The bite was placed 1.5-2 $\mathrm{mm}$ behind the posterior surgical limbus. The knot was tied right in the incision level or slightly behind the incision groove. The suture ends were left long $(4 \mathrm{~mm})$ and laid flat into the prepared scleral pockets (Figs. 1f and $2 \mathrm{f}$ ).

The infusion cannula was removed, the conjunctival peritomy was closed. A subconjunctival injection with 20,000 unit tobramycin and $2.5 \mathrm{mg}$ dexamethasone was performed at the end of the procedure. Postoperatively, topical antibiotic/steroid drops were given four times a day, antibiotic/steroid ointment was instilled at night, for 4 weeks.

\section{Results}

The information of included eyes is presented in Table 1. This technique was successfully used in 48 patients (47 male, one female; mean age \pm SD, $34.8 \pm$ 14.8 years; range, $8-60$ years) presenting with absence of lens capsule due to trauma (open globe injury 43/ 48, closed globe injury 5/48) between May 2007 and December 2013. Cornea scar was presented in $35 / 48$ (72.92 \%) patients. The mean interval from the primary surgery, pars plana vitrectomy or wound closure, to the secondary IOL implantation was $4.5 \pm 1.9$ months. Three kinds of PCIOL were used in our cohort, including

Table 1 Patient information, types of implanted PCIOLs, follow-up period and best corrected visual acuity

\begin{tabular}{ll}
\hline Gender & \\
\hline Male & $47 / 48$ \\
Female & $1 / 48$ \\
Mean Age & $34.8 \pm 14.8$ (range 8-60) years \\
Primary trauma type & \\
Open globe injury & $43 / 48(89.6 \%)$ \\
Closed globe injury & $5 / 48(10.4 \%)$ \\
History of pars plana vitrectomy & $42 / 48(87.5 \%)$ \\
Mean Interval from primary to & $4.5 \pm 1.9$ months \\
PCIOL surgery & \\
Type of implanted IOL & \\
CZ70BD & $35 / 48(72.9 \%)$ \\
AR40e & $8 / 48(16.7 \%)$ \\
Type 67G & $5 / 48(10.4 \%)$ \\
Mean follow-up & $32.3 \pm 10.8$ (range 3-67) months \\
Follow-up $>12$ months & $37 / 48(77.1 \%)$ \\
Pollow-up <12 months & $11 / 48(22.9 \%)$ \\
Post-operation & $(p=0.69)$ \\
\hline & $0.46 \pm 0.34$ \\
Prected Visual acuity & $0.44 \pm 0.34$ \\
\hline
\end{tabular}


PMMA single-piece posterior chamber lenses (CZ70BD, Alcon) in 35/48 eyes, foldable acrylic posterior chamber lenses (AR40e, Advanced Medical Optics) in 8/48 eyes, and black diaphragm aniridia intraocular lens (Type 67G, Morcher) in 5/48 eyes. The mean follow-up was $32.3 \pm$ 10.8 months (range 3-67 months), 37/48 (77.08 \%) patients have a follow-up period over 12 months.

Postoperative complications are shown in Table 2. Postoperatively, transient corneal edema in 37/48 eyes (77.1\%), temporary hypotony $(6-10 \mathrm{mmHg})$ in $11 / 48$ eyes $(22.9 \%)$, vitreous hemorrhage in $4 / 48$ cases $(8.3 \%)$, temporary intraocular pressure elevation in $8 / 48$ eyes (16.7\%), and cystoid macular edema in 5/48 cases (10.4\%) were observed. All these complications were resolved within 4 weeks. Suprachoroidal hemorrhage was observed in $2 / 48$ eyes (4.2\%). In the follow-up period, retinal detachment was found in $2 / 48$ eyes (4.2\%), which were reattached by pars plana vitrectomy and silicon oil tamponade. The mean best corrected visual acuity (LogMAR) remained stable, from $0.46 \pm 0.34$ preoperatively to $0.44 \pm 0.34$ postoperatively ( $T$-test, $p=0.69$ ). Mild IOL tilt $\left(5-10^{\circ}\right)$ was observed in five eyes, and slight IOL decentration $(0.5-1.0 \mathrm{~mm})$ was seen in three cases, detected by Ultrasound Biomicroscope. Figure $2 \mathrm{~g}$ shows a typical post-operative UBM imaging, the IOL was well centered without tilt. In our case series, there were no cases of suture exposure, suture breakage, IOL dislocation, or endophthalmitis during the follow-up period.

\section{Discussion}

Numerous techniques of transscleral fixation of PCIOL have been developed [1]. Covering the suture end with a triangular scleral flap is one of the most common techniques. However, sclera flaps for knot coverage tends to atrophy with time $[1,12-18]$, probably because the area of the flap is too small. Our technique allowed longterm stable placement of PCIOLs, the roof of the scleral pocket offers a greater surface area to cover the suture ends compared with traditional triangular scleral flap.

Table 2 Post-operation complications

\begin{tabular}{lr}
\hline Post-operation complications & \multicolumn{1}{l}{ N. (\%) } \\
\hline Transient corneal edema & $37 / 48(77.1 \%)$ \\
Temporary hypotony & $11 / 48(22.9 \%)$ \\
Vitreous hemorrhage & $4 / 48(8.3 \%)$ \\
Temporary intraocular pressure elevation & $8 / 48(16.7 \%)$ \\
Cystoid macular edema & $5 / 48(10.4 \%)$ \\
Suprachoroidal hemorrhage & $2 / 48(4.2 \%)$ \\
Retinal re-detachment & $2 / 48(4.2 \%)$ \\
IOL tilt (5-10 $)$ & $5 / 48(10.4 \%)$ \\
IOL decentration $(0.5-1.0 \mathrm{~mm})$ & $3 / 48(6.3 \%)$ \\
\hline
\end{tabular}

Hoffman et al. [28] described a similar technique in 2006, in which the sclera pockets were initiated from peripheral clear corneal incisions. However, their technique required two suture passes through the sclera for each haptic, creating twice as many the potential events of vitreous hemorrhage compared with single suturing technique. Our modified procedure facilitated the haptic fixation with a single transscleral pass, and also eliminated the need for suture closure of scleral flap.

An appropriate length of suture end is important to maintain the knot integrity. In theory, a longer suture end is less likely to untie spontaneously, and easier to be laid flat, thus has less chance to break or penetrate the covering-sclera. Using a longer suture end to avoid erosion in PCIOL fixation had been described by Smiddy et al. [4] in 1990 and Chen et al. [27] in 2007. With the length being about $4 \mathrm{~mm}$, the suture end could be covered totally by the scleral pocket, and we found the suture end did not necessarily keep straight under the sclera roof. With this technique, no case of suture breakage was observed in our series during the follow up period.

In the most cases, we used IOLs (Alcon CZ70BD and Type 67G) with a large optic, longer haptics and two eyelets for passing suture thread. They are the appropriate IOLs specially designed for transscleral fixation. But limitation also remains in such kind of rigid IOL: it needs a much bigger incision for the IOL to enter anterior chamber. It is known that bigger incision is associated with more chances of low intraocular pressure, choroidal hemorrhage, and post-operative corneal astigmatism. AR40e is not specially designed for transscleral fixation, but it has been reported to be fixated successfully through sclera [29]. We used foldable IOL (AR40e) for the following reasons: it could be implanted through a small incision, which is associated with better intraocular pressure control, and less chance of choroidal hemorrhage; its haptics are long enough to falicitate suture fixation; the end of haptics could be enlarged through cauterizing slightly to avoid suture slippage.

Limitations of this report include: it is a retrospective study; there was a wide range of the follow-up period in the include patients; possible disadvantage of our technique include sclera pocket associated hemorrhage during operation, and potential complications correlated with intraocular suture ends at haptics fixation sites; one other drawback, as compared to Hoffman pockets, a conjunctival peritomy was needed in our technique. Hoffman's pockets are likely to be better in preserving conjunctiva, which may increase postoperative comfort and be helpful if glaucoma surgery is needed at a later date.

Recently, sutureless technique for PCIOLs implantation [30-36] is becoming popular. Agarwal et al. achieved sutureless by using fibrin glue to close the scleral 
flaps [36] without suture-related complications. However, fibrin glue might be not available everywhere. Wilgucki et al. [37] used a 20 gauge blade to create ciliary sulcus-based sclerotomies to facilitate haptics passing through. The potential events of vitreous hemorrhage may be more than our procedure as the incision number and width are bigger than ours. Three of the 12 cases showed IOL dislocation one year after surgery. Ohta et al. [35] reported a Yfixation technique without using fibrin sealant. But the flap and the groove were closed with nonabsorbable suture to prevent slippage, which was suspected to be a modified suture technique. We prefer suture fixation technique in traumatic aphakic eyes because: none of the commercially available IOLs at present is specially designed for sutureless fixation; sutureless technique requires more transscleral penetrations, which might be associated with more chances of intra-operative and post-operative hypotony, vitreous hemorrhage, and post-operative inflammation; most of the afflicted patients were work population or at a younger age, less transscleral penetration might be associated with reduced suture-related inflammation; suture fixation is more secure to withstand potential reoperation procedures including retinal retachment, sclera compression, and silicone oil tamponade in post-traumatic aphakic eyes. Modification of the present foldable IOLs might facilitate the suture fixation procedure in aphakic eyes. Further prospective clinical trials might provide more evidences for clinical surgeons by comparing the rigid hard IOLs and foldable IOLs, and comparing our technique against the sutureless technique on IOL decentration, IOL tilt, and postoperative complications.

\section{Conclusion}

The modified technique allowed stable placement of PCIOLs in series of post-traumatic aphakic eyes with a wide range of follow-up period. According to our data, covering the suture ends with scleral pockets is an alternative way to avoid suture exposure in scleral-fixated IOL implantation. Our approach could be modified and used for other kinds of IOL or intraocular devices that requires transscleral suture fixation.

\section{Additional file}

Additional file 1: Video illustration of the modified technique for PCIOL suture fixation. (MP4 $16086 \mathrm{~kb}$ )

\section{Abbreviations}

PCIOL: Posterior chamber intraocular lens; IOL: Intraocular lens; BCVA: Best corrective visual acuity; logMAR: Logarithm of the minimum angle of resolution.

\section{Competing interests}

The authors declare that they have no competing interests.

\section{Authors' contributions}

$\mathrm{CL}$ performed the surgery, participated in the design of the study and revised the manuscript; YW participated in the design of the study and drafted the manuscript; $Z Y$ and $Z Z$ collected and analyzed the data; XL carried out critical review and revised the manuscript; $B L$ conceived of the study, analyzed the data, and drafted the manuscript. All authors read and approved the final manuscript.

\section{Acknowledgments}

We thank Mrs Hao Fang and Mrs Ying Chen for their help in retrieving the medical records of this study. This study was supported by Science and Technology Project of Guangdong Province (2013B021800055), and Natural Science Foundation of Guangdong Province (2014A030313197).

Received: 7 May 2015 Accepted: 28 September 2015

Published online: 02 October 2015

\section{References}

1. Por YM, Lavin MJ. Techniques of intraocular lens suspension in the absence of capsular/zonular support. Surv Ophthalmol. 2005;50(5):429-62.

2. Mittelviefhaus $\mathrm{H}$. A modified technique of transscleral suture fixation of posterior chamber lenses. Ophthalmic Surg. 1992;23(7):496-8.

3. Schmidt JC, Nietgen GW, Freisberg L, Neisskenwirth NN. Modified transscleral suture for sulcus fixation of posterior chamber lenses. J Cataract Refract Surg. 2002;28(1):15-7.

4. Smiddy WE, Sawusch MR, O'Brien TP, Scott DR, Huang SS. Implantation of scleral-fixated posterior chamber intraocular lenses. J Cataract Refract Surg. 1990;16(6):691-6.

5. Buckley EG. Scleral fixated (sutured) posterior chamber intraocular lens implantation in children. J AAPOS. 1999;3(5):289-94.

6. Bashshur Z, Ma'luf R, Najjar D, Noureddin B. Scleral fixation of posterior chamber intraocular lenses using fascia lata to cover the knots. Ophthalmic Surg Lasers. 2002;33(6):445-9.

7. Lee W, Yuen HK, Kwok AK. Comparison of outcomes of primary and secondary implantation of scleral fixated posterior chamber intraocular lens. Br J Ophthalmol. 2003;87(12):1459-62.

8. Baykara M, Avci R. Prevention of suture knot exposure in posterior chamber intraocular lens implantation by 4-point scleral fixation technique. Ophthalmic Surg Lasers Imaging. 2004;35(5):379-82.

9. Yang YF, Bunce C, Dart JK, Johnston RL, Charteris DG. Scleral-fixated posterior chamber intraocular lenses in non-vitrectomized eyes. Eye (Lond) 2006;20(1):64-70.

10. Kjeka O, Bohnstedt J, Meberg K, Seland JH. Implantation of scleral-fixated posterior chamber intraocular lenses in adults. Acta Ophthalmol (Copenh). 2008:86(5):537-42.

11. Mimura T, Amano S, Sugiura T, Funatsu H, Yamagami S, Oshika T, et al. 10-year follow-up study of secondary transscleral ciliary sulcus fixated posterior chamber intraocular lenses. Am J Ophthalmol. 2003;136(5):931-3.

12. Solomon K, Gussler JR, Gussler C, Van Meter WS. Incidence and management of complications of transsclerally sutured posterior chamber lenses. J Cataract Refract Surg. 1993;19(4):488-93.

13. Gabric N, Henc-Petrinovic L, Dekaris I. Complications following two methods of posterior chamber intraocular lens suturing. Doc Ophthalmol. 1996:92(2):107-16.

14. Uthoff D, Teichmann KD. Secondary implantation of scleral-fixated intraocular lenses. J Cataract Refract Surg. 1998;24(7):945-50.

15. Sundmacher R, Althaus C, Wester R. Experience with transscleral fixation of posterior chamber lenses. Graefes Arch Clin Exp Ophthalmol. 1991;229(6):512-6.

16. Holland EJ, Daya SM, Evangelista A, Ketcham JM, Lubniewski AJ, Doughman $D J$, et al. Penetrating keratoplasty and transscleral fixation of posterior chamber lens. Am J Ophthalmol. 1992;114(2):182-7.

17. Lindquist TD, Agapitos PJ, Lindstrom RL, Lane SS, Spigelman AV. Transscleral fixation of posterior chamber intraocular lenses in the absence of capsular support. Ophthalmic Surg. 1989;20(11):769-75.

18. McCluskey P, Harrisberg B. Long-term results using scleral-fixated posterior chamber intraocular lenses. J Cataract Refract Surg. 1994;20(1):34-9. 
19. Bardorf CM, Epley KD, Lueder GT, Tychsen L. Pediatric transscleral sutured intraocular lenses: efficacy and safety in 43 eyes followed an average of 3 years. J AAPOS. 2004;8(4):318-24.

20. Lin CP, Tseng HY. Suture fixation technique for posterior chamber intraocular lenses. J Cataract Refract Surg. 2004;30(7):1401-4.

21. Kir E, Kocaturk T, Dayanir V, Ozkan SB, Dundar SO, Aktunc TO. Prevention of suture exposure in transscleral intraocular lens fixation: an original technique. Can J Ophthalmol. 2008;43(6):707-11.

22. Walter KA, Wood TD, Ford JG, Winnicki J, Tyler ME, Reed JW. Retrospective analysis of a novel method of transscleral suture fixation for posteriorchamber intraocular lens implantation in the absence of capsular support. Cornea. 1998;17(3):262-6.

23. Lewis JS. Ab externo sulcus fixation. Ophthalmic Surg. 1991;22(11):692-5.

24. Crouch Jr ER, Pressman SH, Crouch ER. Posterior chamber intraocular lenses: long-term results in pediatric cataract patients. J Pediatr Ophthalmol Strabismus. 1995;32(4):210-8.

25. Omulecki W, Nawrocki J, Sempinska-Szewczyk J. [Posterior chamber implants with scleral fixation in patients with lens subluxation or luxation]. Klin Ocz. 1997;99(2):99-102.

26. Kaynak S, Ozbek Z, Pasa E, Oner FH, Cingil G. Transscleral fixation of foldable intraocular lenses. J Cataract Refract Surg. 2004;30(4):854-7.

27. Chen SX, Lee LR, Sii F, Rowley A. Modified cow-hitch suture fixation of transscleral sutured posterior chamber intraocular lenses: long-term safety and efficacy. J Cataract Refract Surg. 2008;34(3):452-8.

28. Hoffman RS, Fine $\mathbb{H}$, Packer M. Scleral fixation without conjunctival dissection. J Cataract Refract Surg. 2006;32(11):1907-12.

29. Lee KM, Lee EJ, Wee WR, Han YK, Kim MK, Hyon JY. Myopic shift of foldable acrylic intraocular lenses after sulcus fixation. $\mathrm{Br} J$ Ophthalmol. 2012;96(10):1316-9.

30. Totan Y, Karadag R. New approach: removal of silicone oil and trocar assisted sutureless scleral fixated intraocular lens implantation at the same session. International journal of ophthalmology. 2014;7(4):734-6.

31. Walsh MK, Joshi M. Sutureless scleral tunnel intraocular lens fixation in the pediatric population. Retina. 2014;34(4):807-11.

32. Yamane S, Inoue M, Arakawa A, Kadonosono K. Sutureless 27-gauge needle-guided intrascleral intraocular lens implantation with lamellar scleral dissection. Ophthalmology. 2014;121(1):61-6.

33. Benayoun Y, Petitpas S, Turki K, Adenis JP, Robert PY. [Sutureless scleral intraocular lens fixation: report of nine cases and literature review]. J Fr Ophtalmol. 2013;36(8):658-68.

34. Kumar DA, Agarwal A, Jacob S, Prakash G, Gabor SG, Prasad S. Sutureless scleral-fixated posterior chamber intraocular lens. J Cataract Refract Surg. 2011;37(11):2089-90.

35. Ohta T, Toshida H, Murakami A. Simplified and safe method of sutureless intrascleral posterior chamber intraocular lens fixation: Y-fixation technique. J Cataract Refract Surg. 2014;40(1):2-7.

36. Agarwal A, Kumar DA, Jacob S, Baid C, Srinivasan S. Fibrin glue-assisted sutureless posterior chamber intraocular lens implantation in eyes with deficient posterior capsules. J Cataract Refract Surg. 2008;34(9):1433-8.

37. Wilgucki JD, Wheatley HM, Feiner L, Ferrone MV, Prenner JL. One-Year Outcomes of Eyes Treated with a Sutureless Scleral Fixation Technique for Intraocular Lens Placement or Rescue. Retina. 2014;35(5):1036-40.

\section{Submit your next manuscript to BioMed Central and take full advantage of:}

- Convenient online submission

- Thorough peer review

- No space constraints or color figure charges

- Immediate publication on acceptance

- Inclusion in PubMed, CAS, Scopus and Google Scholar

- Research which is freely available for redistribution 